Sharif University of Technology
Scientia Iranica
Transactions E: Industrial Engineering
hCIENTIA

\title{
Multistage supply chain production-inventory model with collaborative preservation technology investment
}

\author{
C.-C. Chang ${ }^{\mathrm{a}, \mathrm{b}}$, C.-J. Lu ${ }^{\mathrm{c}, \mathrm{d}}$, and C.-T. Yang,* \\ a. School of Medical Informatics, Chung-Shan Medical University, Taichung 40201, Taiwan. \\ b. IT Office, Chung Shan Medical University Hospital, Taichung 40201, Taiwan. \\ c. Graduate Institute of Business Administration, Fu Jen Catholic University 242062, Taiwan. \\ d. International Business School, Beijing Foreign Studies University, China. \\ e. Department of International Business Management, Chien Hsin University of Science and Technology, Taoyuan 320312, Taiwan.
}

Received 21 April 2019; received in revised form 30 May 2020; accepted 26 September 2020

\section{KEYWORDS \\ Inventory \\ management; \\ Multistage supply \\ chain; \\ Deteriorating item; \\ Preservation \\ technology.}

\begin{abstract}
This paper investigates a multistage production-inventory model for deteriorating items, including raw materials and finished goods, based on collaborative preservation technology investment. The major purpose is to determine the optimal materials supply, production delivery, replenishment, and investment policies for the retailer and manufacturer in which the joint total profit of the integrated system is maximized. Mathematical programming analysis is employed to ascertain the optimal solutions for the retailer and manufacturer. Furthermore, several numerical examples are presented to demonstrate solution process and verify the concavity of the proposed model. Sensitivity analyses with respect to major parameters are also performed. The numerical results show that market demand, fixed shipping cost, production rate, manufacturer's sales price, and holding cost of finished good may affect the optimal number of shipments. In addition, when collaborative preservation technology investment becomes an option, the effect of the deterioration rate on the shipping and ordering quantity will be reduced through investment in improving deterioration of raw material or finished good. Finally, the increase in the amount of raw materials used to produce a finished product implies that the amount of finished goods produced by the original material is reduced; therefore, the collaborative preservation technology investment is increased.
\end{abstract}

(C) 2022 Sharif University of Technology. All rights reserved.

\section{Introduction}

Recently, commercial developments have demonstrated that effective integration of enterprises is key to survival in a highly competitive industry. Similarly, inventory management studies should consider the entire supply chain membership and establish an integrated inventory model rather than adopt a retailer's or

\footnotetext{
*. Corresponding author. Tel.: +886-3-4581196\#6123
} E-mail address:122300@mail.tku.edu.tw (C.T. Yang)

doi: $10.24200 /$ sci. 2020.53357 .3200 manufacturer's viewpoint alone. The application of the production-inventory model to manufacturers and retailers in supply chain has been discussed extensively. Goyal [1] first developed an integrated inventory model based on the Economic Order Quantity (EOQ) model to determine the optimal joint inventory policy for a single vendor and single buyer. Banerjee [2] developed a joint economic-lot-size model in which a vendor produces items to be ordered for a buyer on a "lotfor-lot" basis. Goyal [3] employed Banerjee's [2] model to relax the assumption of the "lot-for-lot" policy and demonstrated that the joint total relevant cost of the proposed model was lower than or equal to that in 
Banerjee [2]. Lu [4] subsequently extended Goyal's [3] model to consider one-vendor and multiple buyers in an integrated inventory model and relaxed the assumption that shipments cannot be triggered before the entire production batch is completed. Goyal [5] further applied Lu's [4] model to suggest that the shipment size to the buyer of a production batch should be increased by a fixed factor. Hill [6] generalized the model of Goyal [5] by taking the geometric growth factor as a decision variable and demonstrating numerically that his policy outperformed both the equal shipment size policy and the policy adopted by Goyal [5]. Goyal and Nebebe [7] attempted to exploit the benefits of both equal-size and geometric policies and suggested a simple geometric-then-equal policy that produced positive results. Kelle et al. [8] first proposed a production and shipping policy where the buyer's order was delivered in $n$ shipments of equal size and the vendor's production lot size could also be an integer, $m$, multiple of the shipment size, where $m$ is different from $n$. Giri and Roy [9] developed a production-inventory model in which the vendor offers a quantity discount to motivate the buyers to buy a larger quantity and delivers an unequal size per shipment. Thereafter, many researchers (e.g., Sana [10], Wu and Chen [11], Lin and Ho [12], Ouyang et al. [13], Muniappan et al. [14], Bhunia et al. [15], Teimoury and Kazemi [16]) continued to propose additional ordering and shipping policies for integrated inventory models. However, previous studies of production-inventory models only explored the production, transport, or ordering strategies, or all strategies together, but did not consider the effect of multi-stages of raw material supply, production delivery, and order sales, being necessary for a complete supply chain system.

For items with a high deterioration rate, using preservation technology to improve the investment is a major concern for inventory management. Beck et al. [17] reported that the fast-moving consumer goods market loses 18 billion annually because of stock shortages in Europe alone. In the US grocery industry, approximately $15 \%$ of goods are discarded before selling because of spoilage [18]. Based on the empirical study by the profit experts [19], a $20 \%$ reduction in waste from deterioration could increase gross profits by $33 \%$. These results indicate that the management of deteriorating goods is critical when performing inventory management, especially in the retail grocery industry. Companies require a more robust inventory management system to reduce losses because of deterioration. The inventory models for deteriorating items have been widely discussed by scholars after the study of Ghare and Schrader [20]. The natural process of deterioration is unavoidable, but it can be delayed by investing in special storage equipment and procedures. For example, when food is stored and packaged, maintaining its quality permanently is impossible, but equipment and procedures can extend its shelf life. Cold storage or freezers also help to prevent microbial and chemical corruption. Freezing and vacuum technology can remove moisture from food, pharmaceuticals, or agricultural products, thereby reducing humidity to enable long-term storage at room temperature [21]. In summary, deterioration rate can be slowed down using facilities equipped with preservation technology or maintaining proper environmental conditions. Hsu et al. [22] developed a deteriorating inventory model in which the retailer is allowed to invest in preservation technology to improve the deterioration. They concluded that the higher the deterioration rate of a product, the greater the necessary investment in preservation technology. Dye and Hsieh [23] extended the model of Hsu et al. [22] by assuming that the cost of preservation technology is a function of the length of the replenishment cycle. Furthermore, time-varying deterioration and reciprocal time-dependent partial backlogging rates were considered in the model of Dye and Hsieh [23]. Dye [24] also employed the model of Hsu et al. [22] and studied investment in preservation technology and inventory decisions concerning a retailer's non-instantaneous deteriorating items. The generalized productivity of invested capital and deterioration as well as timedependent partial backlogging rates were used to obtain robust and general results concerning inventory management. He and Huang [25] and Zhang et al. [26] studied both investment in preservation technology and pricing strategies and developed an inventory model for deteriorating items. Mishra et al. [27] studied the characteristics of preservation technology investment in the case of deteriorating items with stock and price-dependent demand. Mishra et al. [28] further developed an inventory model for deteriorating items with not only controllable deterioration rate but also trade credit. Other relevant articles include Singh and Sharm [29], Shah et al. [30], Yang et al. [31], Singh and Rathore [32], Tsao [33], and Bardhan et al. [34]. However, the research concerning preservation techniques described in all these studies has been done from the retailer perspective and does not account for supply chain integration. When the preservation technology necessary for reducing the deterioration rate of items requires considerable investment, a single enterprise cannot afford it. However, in an integrated supply chain system, the manufacturer and retailer can agree to jointly invest capital in reducing the deterioration rate of items and achieve global optimization. Consequently, devising an optimal investment strategy for balancing the cost of deterioration against the cost of investment is a major challenge that must be addressed in the field of integrated production and inventory problems. 
Besides, quality warrants discussion in supply chain inventory management. Product quality can vary considerably depending on the manufacturer's production process. Retailers may thus assess the product quality when the order is received before stocking it for immediate or later use. Quality-related costs include prevention costs, identification and inspection costs, internal failure costs, and external failure costs; managers make trade-offs between these costs to achieve the appropriate level of quality [35]. Inventory models accounting for defective products have also been proposed. Rosenblatt and Lee [36] considered the effect of imperfect production processes in an EPQ model. Kim and Hong [37] applied the model of Rosenblatt and Lee [36] to determine the optimal production run length for production processes of deteriorating goods. Salameh and Jaber [38] proposed a modified EPQ model with defective items which can be sold as a single batch at a discounted price at the end of the screening process. Recently, Nobil et al. [39] applied an EPQ model with an imperfect production system including the purchasing of raw materials. Afterwards, numerous studies concerning imperfect production processes have been published including Sana [40], Treviño-Garza et al. [41], Hsu and Hsu [42], Jaggi et al. [43], Kang et al. [44], Jain et al. [45], and Yang et al. [46].

Extending the scope of the literature, this study examined the optimal production, shipping, ordering, and preservation technology investment policies for an integrated multistage supply chain system with respect to deteriorating raw materials and finished products with a controllable deterioration rate, collaborative preservation technology investment, and defective finished products. The main features of this paper different from previous studies are described as follows: To the best of our knowledge, no study has yet considered a three-stage supply chain, namely raw materials supply, production delivery, and order sales, to develop a production-inventory model with defective finished products. Further, the concept of a co-investment agreement in preservation technology investment among supply chain members is used in the proposed model. In terms of model formulation, the total profits of the retailer and manufacturer are established and then integrated to obtain the joint total profit per unit time. The main purpose is to determine the optimal production, delivery, ordering, and investing policies for the retailer and manufacturer so as to maximize the joint total profit per unit time. Because of the complexity of the model, determining closed-form optimal solutions and directly checking the concavity of the profit function are difficult. Alternatively, an attempt is made to develop an algorithm to obtain optimal solutions for the supply chain system and then, verify the concavity of the proposed model through numerical analysis. Furthermore, several numerical examples are presented to demonstrate the procedures for solving the problem. A sensitivity analysis with respect to major parameters is also conducted to ascertain several managerial implications that may provide managers with a useful decision-making tool.

\section{Notation and assumptions}

This paper uses the following notations to discuss the multistage supply chain production-inventory model:

$D \quad$ The demand rate

$P \quad$ The manufacturer's production rate

$A_{R} \quad$ The retailer's ordering cost of finished products per order

$A_{M} \quad$ The manufacturer's ordering cost of raw material per order

$r \quad$ The number of raw materials used to produce a finished product

$S \quad$ The manufacturer's setup cost per production cycle

$s \quad$ The retailer's inspection cost per unit

$c_{1} \quad$ The manufacturer's raw material cost per unit

$c_{2} \quad$ The manufacturer's production cost per unit

$\nu \quad$ The manufacturer's sales price per unit

$p \quad$ The retailer's selling price per unit

$h_{b} \quad$ The retailer's holding cost per unit per unit time

$h_{m} \quad$ The manufacturer's holding cost of raw material per unit per unit time

$h_{v} \quad$ The manufacturer's holding cost of finished goods per unit per unit time

$u \quad$ The manufacturer's treatment cost per defective item

$C_{T} \quad$ The retailer's fixed shipping cost per shipment

$C_{t} \quad$ The retailer's variable shipping cost per unit

$\theta_{1} \quad$ The original rate of deterioration of the raw materials

$\theta_{2} \quad$ The original rate of deterioration of the finished goods

$\lambda$ The rate of defective finished products, where $\lambda \in(0,1)$

$\xi \quad$ The preservation technology investment for reducing the rate of deterioration to preserve the products; a decision variable

$m(\xi) \quad$ The proportional reduction of the deterioration rate; a function of $\xi$ 
Q The retailer's order quantity; a decision variable

$n$

Number of shipments from the manufacturer to the retailer per production cycle; a decision variable The quantity of non-defective items sent from the manufacturer to the retailer per shipment; a decision variable

$T_{b} \quad$ Length of the retailer's replenishment cycle; a decision variable

$T_{v} \quad$ Length of the manufacturer's production cycle; a decision variable

$T_{s} \quad$ Length of the manufacturer's period of production per production cycle; a decision variable

$T_{p} \quad$ Length of time for the manufacturer to make and deliver the first batch of finished products to the retailer

The superscript represents the optimal value

This paper uses the following assumptions:

1. The multistage supply chain system considers a single manufacturer, single retailer, single material, and single commodity.

2. The finished goods produced by the manufacturer contain defective items and must be inspected by the retailer. No errors occur during the inspection process. In addition, to simplify the problem, this model does not consider the occurrence of defective materials

3. The manufacturer's production rate of nondefective products is finite and greater than the demand rate, i.e., $(1-\lambda) P>D$. Otherwise, no inventory problems would occur.

4. The retailer orders $Q$ units of multiple sizes and allows the manufacturer to divide the order into $n$ consignments [21,47]. Because the finished products produced by the manufacturer contain defective products at a rate of $\lambda$, the manufacturer may ship $q /(1-\lambda)$ units to the retailer to ensure that the retailer receives $q$ units of non-defective products in each shipment.

5. The original deterioration rates of the raw material and the finished goods are assumed to be $\theta_{1}$ and $\theta_{2}$, respectively. Both of them can be reduced through preservation technology investment at the same rate of $m(\xi)$, where $m(\xi)$ is an increasing function of the preservation technology investment $(\xi)$ and $0<$ $m(\xi)<1$ (please refer to Dye and Hsieh [23], and Dye [24]). That is, the rates of deterioration for raw material and finished products are $[1-m(\xi)] \theta_{1}$ and $[1-m(\xi)] \theta_{2}$, which can be controlled by investment.
Furthermore, the model does not permit the repair or replacement of deteriorated units; items are withdrawn immediately as they deteriorate.

6. The manufacturer and retailer jointly share the preservation technology investment. The proportions of the capital investment that the retailer and manufacturer should invest in machinery equipment are $\alpha$ and $1-\alpha$, respectively, where $0 \leq \alpha \leq 1$.

7. Shortages are not allowed for either the manufacturer or the retailer.

\section{Model formulation and solution}

This paper establishes a multistage integrated supply chain production-inventory model that considers a three-stage supply chain, namely raw material supply, production delivery, and order sales. A single manufacturer and a single retailer are considered in the system. For the retailer, the quantity of finished products per order is $Q$ units and the manufacturer must deliver the order in $n$ batches (the freight cost is borne by the retailer). The manufacturer purchases raw materials from the original material supplier to be able to produce upon receiving the retailer's order. Because the finished products produced by the manufacturer contain defective products at a rate of $\lambda$, the manufacturer may ship $q /(1-\lambda)$ units to the retailer to ensure that the retailer receives $q$ units of nondefective products in each shipment. Thus, the total shipping quantity of finished products in a production cycle (length of the period is $T_{v}$ ) is $Q /(1-\lambda)$. To comply with the Just-In-Time (JIT) inventory system, the manufacturer begins shipping to the retailer when the production quantity reaches units for the first time (length of the period is $T_{p}$ ). The manufacturer then ships $q$ units at regular intervals (length of the period is $T_{b}$ ). Furthermore, because the manufacturer's production rate of finished products is higher than the demand rate, it may stop producing, but continue to ship regularly until the entire ordered quantity has shipped, when the inventory quantity of finished products reaches $I_{\max }$ (length of the period is $T_{S}$ ). The production, delivery, and sales process of the entire multistage supply chain system is depicted in Figure 1. The inventory levels of the manufacturer's materials and products and the retailer's goods in a complete production cycle are represented in Figure 2.

On the basis of the aforementioned notation and assumptions, the total profit per unit time for each stage of the supply chain was established as follows.

\subsection{Retailer's total profit}

Because finished products from the manufacturer contain defective products at a rate of $\lambda$, the retailer receives $q /(1-\lambda)$ units that are immediately inspected in each shipment. The good items ( $q$ units) are stored 


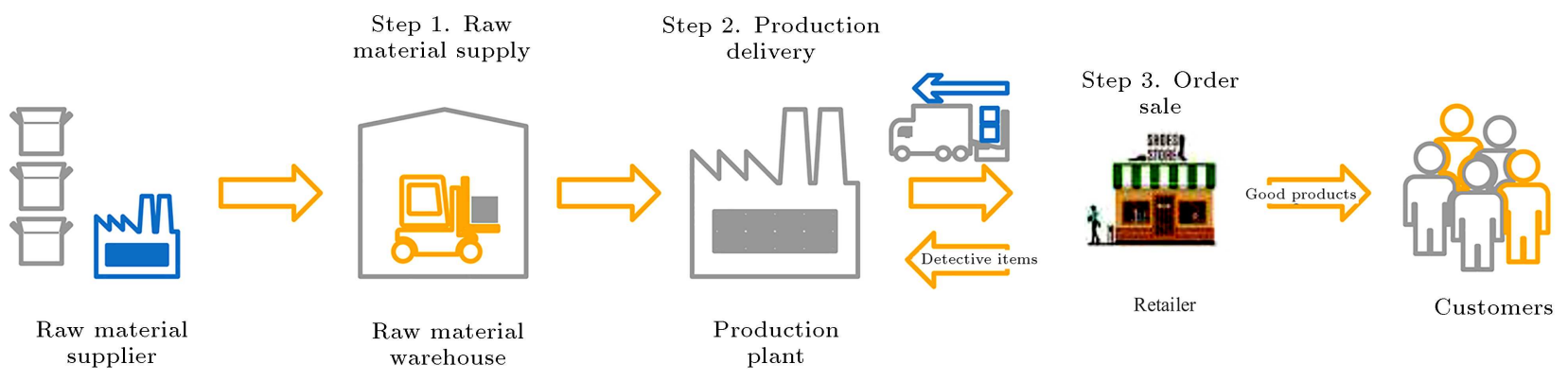

Figure 1. Multistage supply chain considering defective products.

Inventory level (retailer's good)

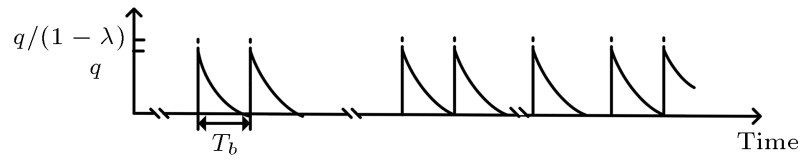

Inventory level (manufacturer's product)

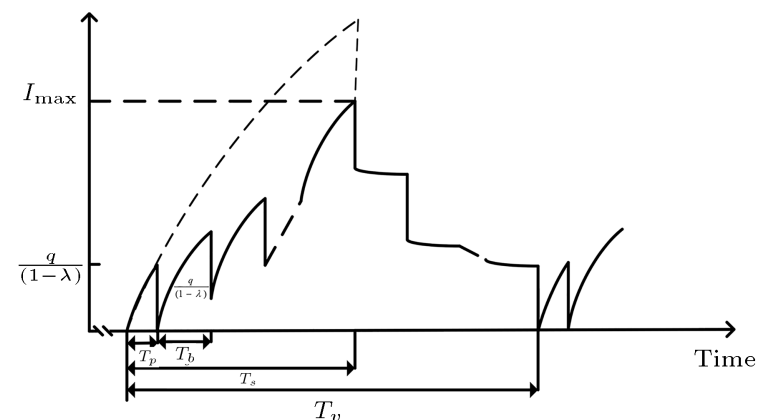

Inventory level (manufacturer's material)

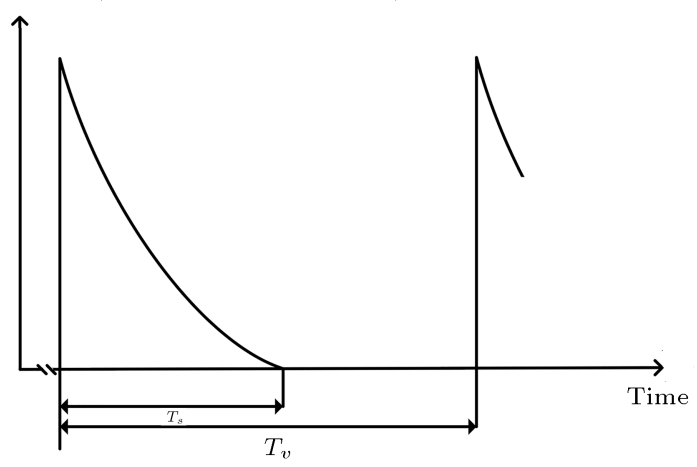

Figure 2. Inventory levels of the manufacturer's materials and products and retailer's goods in a complete production cycle.

and then, sold. The retailer's inventory level of finished products at time $t$ during the replenishment cycle is reduced because of market demand and the deterioration (Figure 2), and it is represented by the following differential equation:

$$
d I_{R}(t) / d t+[1-m(\xi)] \theta_{2} I_{R}(t)=-D, \quad 0 \leq t \leq T_{b}
$$

Solving Eq. (1) with the boundary condition $I_{R}\left(T_{b}\right)=$ 0 yields:

$$
\begin{aligned}
I_{R}(t) & =\frac{D}{[1-m(\xi)] \theta_{2}}\left\{e^{[1-m(\xi)] \theta_{2}\left(T_{b}-t\right)}-1\right\}, \\
0 & \leq t \leq T_{b} .
\end{aligned}
$$

From Eq. (2), the quantity of non-defective items shipped from the manufacturer to the retailer per shipment $q=I_{R}=0$ can be obtained through the following equation:

$$
q=I_{R}(0)=\frac{D}{[1-m(\xi)] \theta_{2}}\left\{e^{[1-m(\xi)] \theta_{2} T_{b}}-1\right\} .
$$

The retailer's total profit per unit time is determined by sales revenue, ordering cost, inspection cost, purchasing cost, holding cost, transportation cost, and preservation technology investment, which are evaluated as follows:

(a) The sales revenue per replenishment cycle is $p D T_{b}$.

(b) The ordering cost per replenishment cycle is $A_{R}$.

(c) The inspection cost per replenishment cycle is:

$$
\begin{aligned}
\frac{s q}{(1-\lambda)}= & \frac{s D}{(1-\lambda)[1-m(\xi)] \theta_{2}} \\
& \left\{e^{[1-m(\xi)] \theta_{2} T_{b}}-1\right\} .
\end{aligned}
$$

(d) Although the manufacturer delivers $q /(1-\lambda)$ units to the retailer per replenishment, $\lambda q /(1-\lambda)$ defective units will be immediately detected by the retailer and returned to the manufacturer. Thus, the retailer's purchasing cost is:

$$
v q=\frac{v D}{[1-m(\xi)] \theta_{2}}\left\{e^{[1-m(\xi)] \theta_{2} T_{b}}-1\right\} .
$$

(e) The retailer's transportation cost consists of fixed and variable costs per replenishment cycle and is given by:

$$
\begin{aligned}
C_{T}+ & \frac{C_{t} q}{(1-\lambda)}=C_{T}+\frac{C_{t} D}{(1-\lambda)[1-m(\xi)] \theta_{2}} \\
& \left\{e^{[1-m(\xi)] \theta_{2} T_{b}}-1\right\} .
\end{aligned}
$$


(f) The retailer's holding cost is:

$$
\begin{aligned}
h_{b} & \int_{0}^{T_{b}} I_{R}(t) d t \\
& =h_{b} \int_{0}^{T_{b}} \frac{D}{[1-m(\xi)] \theta}\left[e^{[1-m(\xi)] \theta\left(T_{b}-t\right)}-1\right] d t \\
& =\frac{h_{b} D}{[1-m(\xi)]^{2} \theta_{2}^{2}}\left\{e^{[1-m(\xi)] \theta_{2} T_{b}}\right. \\
& \left.-[1-m(\xi)] \theta_{2} T_{b}-1\right\} .
\end{aligned}
$$

(g) The preservation technology investment, $\xi$, is shared between the retailer and manufacturer and the proportion of the retailer's investment is $\alpha$ $(0 \leq \alpha \leq 1)$; thus, the retailer's investment to reduce the deterioration rate per cycle is denoted by $\alpha \xi T_{b}$.

On the basis of these details, the retailer's total profit per unit time, denoted by $T P_{b}\left(T_{b}, \xi\right)$, can be obtained:

$$
\begin{gathered}
T P_{b}\left(T_{b}, \xi\right)=\frac{1}{T_{b}}\left\{(p-v) D T_{b}-A_{R}-C_{T}\right. \\
-\frac{\left(s+C_{t}\right) D}{(1-\lambda)[1-m(\xi)] \theta_{2}}\left\{e^{[1-m(\xi)] \theta_{2} T_{b}}-1\right\} \\
-\frac{\left\{h_{b}+[1-m(\xi)] \theta_{2} v\right\} D}{[1-m(\xi)]^{2} \theta_{2}^{2}}\left\{e^{[1-m(\xi)] \theta_{2} T_{b}}\right. \\
\left.\left.-[1-m(\xi)] \theta_{2} T_{b}-1\right\}\right\}-\alpha \xi
\end{gathered}
$$

\subsection{Manufacturer's total profit}

The inventory levels of the manufacturer's material in a complete production cycle are depicted in Figure 2. In a production cycle, on receiving a retailer's order ( $Q$ units), the manufacturer places orders with the original material supplier for processing and production material. Assuming that one unit of finished product requires $r$ units of raw materials and the material deteriorates during storage, the manufacturer's inventory level fluctuates due to the use of materials for production and the deterioration of the material during the time interval $\left[0, T_{s}\right]$. The manufacturer's inventory level of raw materials changes at time $t$ at the time interval $\left[0, T_{s}\right]$ and is represented by the following differential equation:

$$
\begin{aligned}
& d I_{M}(t) / d t+[1-m(\xi)] \theta_{1} I_{M}(t)=-r P \\
& 0 \leq t \leq T_{s}
\end{aligned}
$$

By using the boundary condition $I_{M}\left(T_{s}\right)=0$, the manufacturer's inventory level of materials per production cycle can be obtained:

$$
\begin{aligned}
I_{M}(t) & =\frac{r P}{[1-m(\xi)] \theta_{1}}\left\{e^{[1-m(\xi)] \theta_{1}\left(T_{s}-t\right)}-1\right\} \\
0 & \leq t \leq T_{s} .
\end{aligned}
$$

From Eq. (6), the total amount of raw materials per production cycle $q_{M}=I_{M}(0)$ can be obtained as follows:

$$
q_{M}=I_{M}(0)=\frac{r P}{[1-m(\xi)] \theta_{1}}\left\{e^{[1-m(\xi)] \theta_{1} T_{s}}-1\right\} .
$$

To comply with the spirit of JIT, as the manufacturer produces $q /(1-\lambda)=Q /[n(1-\lambda)]$ units of finished goods, it delivers goods to the retailer immediately at the beginning of the production cycle. Then, the number of fixed shipments $(q /(1-\lambda)$ units $)$ is repeated at every interval $T_{b}$. The total number of shipments in a production cycle is $n$ (see Figure 2 ). In each shipment, $\lambda q /(1-\lambda)$ units of defective products are returned by the retailer and discarded.

The manufacturer's inventory level of finished products changes because of the production and deterioration during $\left[0, T_{s}\right]$. Because the manufacturer's production rate for non-defective products is finite and greater than the demand rate, the manufacturer stops production once the inventory reaches a certain level $I_{\max }$. Figure 3 illustrates the manufacturer's and retailer's cumulative inventory. From Figure 3, the manufacturer's finished goods inventory level at time $t$ during $\left[0, T_{s}\right]$ can be discerned through the following differential equation:

$$
d I_{p}(t) / d t+[1-m(\xi)] \theta_{2} I_{p}(t)=P, \quad 0 \leq t \leq T_{s} .
$$

Based on the boundary condition $I_{p}(0)=0$, the manufacturer's inventory level of finished goods can be obtained:

$$
\begin{aligned}
& I_{p}(t)=\frac{P}{[1-m(\xi)] \theta_{2}}\left\{1-e^{-[1-m(\xi)] \theta_{2} t}\right\}, \\
& 0 \leq t \leq T_{s} .
\end{aligned}
$$

As the first order of goods $(q /(1-\lambda)$ units $)$ completes (length of the period is $T_{p}$ ), the manufacturer immediately ships them to the retailer. Thus:

$$
\begin{gathered}
I_{p}\left(T_{p}\right)=q /(1-\lambda)=P\left(1-e^{-[1-m(\xi)] \theta_{2} T_{p}}\right) \\
/[1-m(\xi)] \theta_{2},
\end{gathered}
$$

which implies: 


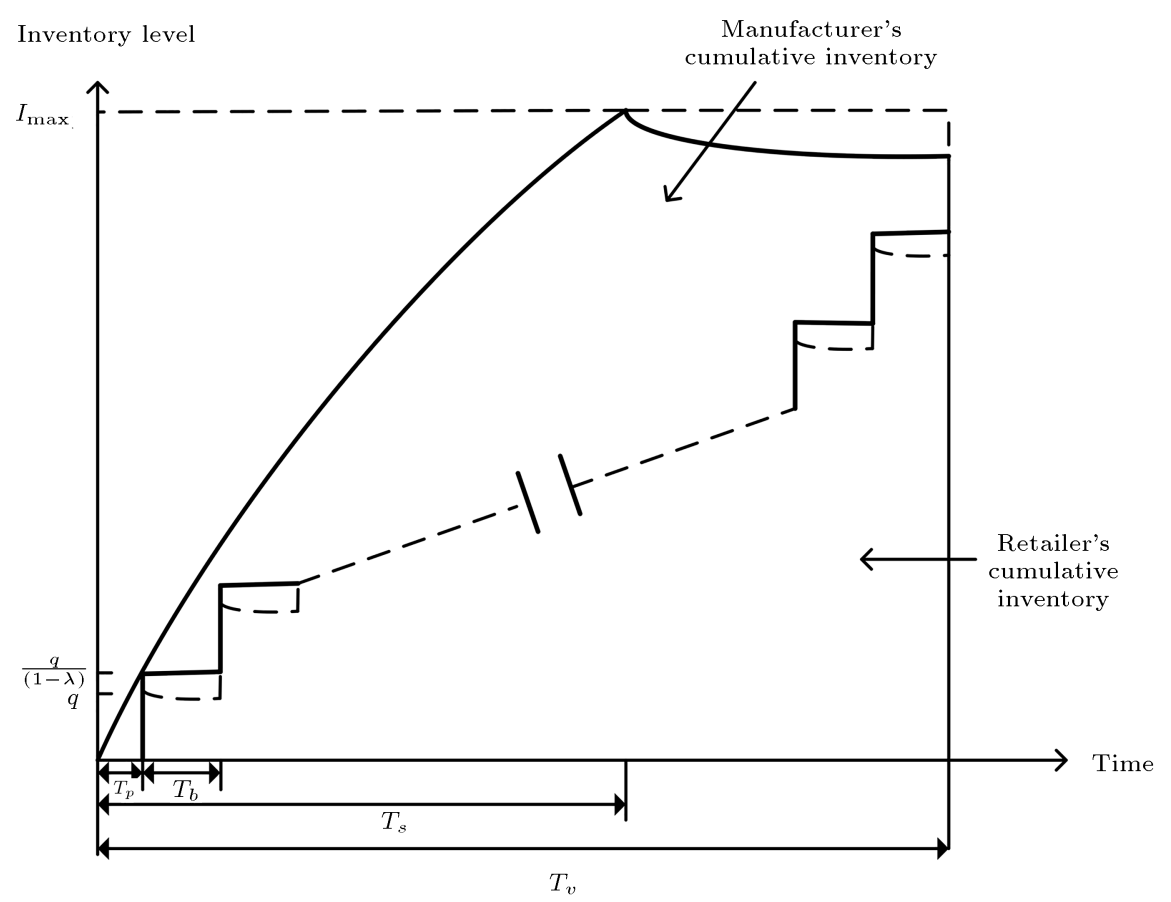

Figure 3. Manufacturer's and retailer's cumulative inventory of finished goods.

$$
T_{p}=\frac{1}{[1-m(\xi)] \theta_{2}} \ln \left(\frac{(1-\lambda) P}{(1-\lambda) P-[1-m(\xi)] \theta_{2} q}\right)
$$

where $q$ is taken from Eq. (3).

During $\left[T_{s}, T_{v}\right]$, the manufacturer is no longer producing, and its inventory level decreases because of deterioration; thus, the inventory level of finished goods at time $t$ is governed by the following differential equation:

$$
\frac{d I_{d}(t)}{d t}+[1-m(\xi)] \theta_{2} I_{d}(t)=0, \quad T_{s} \leq t \leq T_{v} .
$$

Similarly, the manufacturer's inventory level of the finished goods during $\left[T_{s}, T_{v}\right]$ with boundary condition $I_{d}\left(T_{v}\right)=n q /(1-\lambda)$ can be obtained by solving Eq. (11) as follows:

$$
I_{d}(t)=\frac{n q e^{[1-m(\xi)] \theta_{2}\left(T_{v}-t\right)}}{1-\lambda}, \quad T_{s} \leq t \leq T_{v},
$$

where $q$ is taken from Eq. (3).

From Eqs. (9) and (12) and $I_{p}\left(T_{s}\right)=I_{d}\left(T_{s}\right)$, it can be determined that:

$$
\begin{aligned}
T_{s}= & \frac{1}{[1-m(\xi)] \theta_{2}} \ln \\
& {\left[\frac{(1-\lambda) P+[1-m(\xi)] \theta_{2} n q e^{[1-m(\xi)] \theta_{2} T_{v}}}{(1-\lambda) P}\right] . }
\end{aligned}
$$

Similarly, the manufacturer's total profit per unit time includes sales revenue, setup cost, ordering cost, material cost, production cost, defective item processing cost, holding cost, and preservation technology investment. These components are evaluated as follows:

(a) The manufacturer's sales revenue per production cycle is:

$$
v Q=v n q=\frac{v n D}{[1-m(\xi)] \theta_{2}}\left\{e^{[1-m(\xi)] \theta_{2} T_{b}}-1\right\} .
$$

(b) The manufacturer's setup cost per production cycle is $S$.

(c) The manufacturer's ordering cost for material per production cycle is $A_{M}$.

(d) The manufacturer's material cost per production cycle is:

$$
c_{1} q_{M}=\frac{c_{1} r P}{[1-m(\xi)] \theta_{1}}\left\{e^{[1-m(\xi)] \theta_{1} T_{s}}-1\right\} .
$$

(e) The manufacturer's production cost per production cycle is $c_{2} P T_{s}$.

(f) The manufacturer's holding cost contains two parts: raw material and finished products. The holding cost of raw materials is:

$$
\begin{aligned}
h_{m} \int_{0}^{T_{s}} I_{M}(t) d t & =\frac{h_{m} r P}{[1-m(\xi)]^{2} \theta_{1}^{2}} \\
& \left\{e^{[1-m(\xi)] \theta_{1} T_{s}}-[1-m(\xi)] \theta_{1} T_{s}-1\right\} .
\end{aligned}
$$


With respect to the holding cost of finished goods, the manufacturer's total inventory per production cycle is equal to the manufacturer's cumulative inventory minus the retailer's cumulative inventory (see Figure 3 ), given by $\int_{0}^{T_{s}} I_{p}(t) d t+\int_{T_{s}}^{T_{v}} I_{d}(t) d t-$ $\left[q T_{b} /(1-\lambda)\right][1+2+\cdots+(n-1)]$. Therefore, the holding cost of finished goods is:

$$
\begin{aligned}
h_{v}\left\{\int_{0}^{T_{s}} I_{p}(t) d t+\int_{T_{s}}^{T_{v}} I_{d}(t) d t-\left[q T_{b} /(1-\lambda)\right]\right. \\
\quad[1+2+\cdots+(n-1)]\} \\
\quad=h_{v}\left\{\frac { P } { [ 1 - m ( \xi ) ] \theta _ { 2 } } \left\{e^{-[1-m(\xi)] \theta_{2} T_{s}}\right.\right. \\
\left.\quad+[1-m(\xi)] \theta_{2} T_{s}-1\right\} \\
\quad+\frac{n q}{(1-\lambda)[1-m(\xi)] \theta_{2}}\left\{e^{[1-m(\xi)] \theta_{2}\left(T_{v}-T_{s}\right)}-1\right\} \\
\left.\quad-\frac{n(n-1) q T_{b}}{2(1-\lambda)}\right\} .
\end{aligned}
$$

(g) Because $q /(1-\lambda)$ units of defective products are returned by the retailer per shipment, the manufacturer's processing cost for returned defective products in a production cycle is $u n \lambda q /(1-\lambda)$.

(h) Similar to the retailer, the preservation technology investment $\xi$ reduced the deterioration rate which is shared between the retailer and manufacturer. Because the proportion of the cost that the manufacturer shares is $1-\alpha(0 \leq \alpha \leq 1)$, the preservation technology investment reduces the deterioration rate per cycle for the manufacturer by $(1-\alpha) \xi T_{v}$.

Consequently, the manufacturer's total profit per unit time, denoted by $T P_{v}\left(T_{v}, T_{s}, n, \xi\right)$, is:

$$
\begin{aligned}
& T P_{v}\left(T_{v}, T_{s}, n, \xi\right)= \\
& \quad \frac{1}{T_{v}}\left\{v n q-\left(c_{1} r+c_{2}\right) P T_{s}-S-A_{M}\right. \\
& -\frac{\left\{h_{m}+[1-m(\xi)] \theta_{1} c_{1}\right\} r P}{[1-m(\xi)]^{2} \theta_{1}^{2}} \times\left\{e^{[1-m(\xi)] \theta_{1} T_{s}}\right. \\
& \left.-[1-m(\xi)] \theta_{1} T_{s}-1\right\}-\frac{h_{v} P}{[1-m(\xi)] \theta_{2}} \\
& \quad \times\left\{e^{-[1-m(\xi)] \theta_{2} T_{s}}+[1-m(\xi)] \theta_{2} T_{s}-1\right\}
\end{aligned}
$$

$$
\begin{aligned}
& +\frac{n h_{v} q\left\{e^{[1-m(\xi)] \theta_{2}\left(T_{v}-T_{s}\right)}-1\right\}}{(1-\lambda)[1-m(\xi)] \theta_{2}} \\
& \left.-\frac{n(n-1) h_{v} q T_{b}}{2(1-\lambda)}-\frac{u n \lambda q}{1-\lambda}\right\}-(1-\alpha) \xi
\end{aligned}
$$

where $q$ is taken from Eq. (3).

\subsection{Joint total profit of the system}

Because the manufacturer and the retailer have decided to share resources and engage in a mutually beneficial cooperation, the joint total profit per unit time, which is a function of $T_{v}, T_{s}, T_{b}, n$, and $\xi$, denoted by $\operatorname{JTP}\left(T_{v}, T_{s}, T_{b}, n, \xi\right)$, can be obtained as the sum of the manufacturer's and retailer's total profit per unit time, given by:

$$
\begin{gathered}
J T P\left(T_{v}, T_{s}, T_{b}, n, \xi\right)=T P_{b}\left(T_{b}, \xi\right) \\
\quad+T P_{v}\left(T_{v}, T_{s}, n, \xi\right)
\end{gathered}
$$

where $T P_{b}\left(T_{b}, \xi\right)$ and $T P_{v}\left(T_{v}, T_{s}, n, \xi\right)$ are solved by Eqs. (4) and (14), respectively.

From Eqs. (10) and (13) and that $T_{v}=T_{p}+$ $n T_{b}, \operatorname{JTP}\left(T_{v}, \quad T_{s}, T_{b}, n, \xi\right)$ can be reduced to $\operatorname{JTP}\left(T_{b}, n, \xi\right)$. Now, the objective is to determine the optimal value of $\left(T_{b}, n, \xi\right)$ for maximizing the joint total profit per unit time. Because of the complexity of the model and because $n$ is an integer, finding closed-form solutions for $T_{b}, n$, and $\xi$ and directly checking the concavity of profit function are difficult. Thus, alternatively, the concavity will be verified by numerical analysis in the next section and an algorithm is developed to obtain the solutions for the joint total profit per unit time.

\section{Algorithm 1.}

Step 1. Set $n=1$.

Step 2. Find $T_{b(n)}$ and $\xi_{(n)}$ by solving the simultaneous equations:

$$
\begin{aligned}
& \partial \operatorname{JTP}\left(T_{b}, n, \xi\right) / \partial T_{b}=0 \text { and } \\
& \partial \operatorname{JTP}\left(T_{b}, n, \xi\right) / \partial \xi=0 .
\end{aligned}
$$

Step 3. Substitute $n, T_{b(n)}$, and $\xi_{(n)}$ into Eq. (15) to calculate $\operatorname{JTP}\left(T_{b(n)}, \xi_{(n)}, n\right)$.

Step 4. Set $n=n+1$ and repeat Steps 2 and 3 to obtain $\operatorname{JTP}\left(T_{b(n+1)}, \xi_{(n+1)}, n+1\right)$.

Step 5. Compare $\operatorname{JTP}\left(T_{b(n+1)}, \xi_{(n+1)}, n+1\right)$ with $\operatorname{JTP}\left(T_{b(n)}, \xi_{(n)}, n\right)$.

(i) If $\operatorname{JTP}\left(T_{b(n+1)}, \xi_{(n+1)}, n+1\right) \leq \operatorname{JTP}\left(T_{b(n)}\right.$, $\left.\xi_{(n)}, n\right)$, then $\left(T_{b(n)}, \xi_{(n)}, n\right)$ is the optimal solution and the process is finished. 
(ii) If $\operatorname{JTP}\left(T_{b(n+1)}, \xi_{(n+1)}, n+1\right)>\operatorname{JTP}\left(T_{b(n)}\right.$, $\left.\xi_{(n)}, n\right)$, return to Step 4 .

After obtaining the optimal solution of $\left(T_{b}, \xi, n\right)$, the manufacturer's optimal number of shipments and quantity of items shipped, the retailer's optimal order quantity, the preservation technology investment, and the total joint profits per unit time are determined.

\section{Numerical analysis}

In this section, we illustrate the foregoing theoretical results and aforementioned algorithm using the following numerical examples:

Example 1: Consider an inventory situation where $D=1000$ units/year, $P=8000$ units/year, $A_{R}=$ $\$ 100 /$ order, $a_{m}=\$ 500 /$ order, $S=\$ 800 /$ setup, $v=$ $\$ 20 /$ unit, $h_{b}=0.5 /$ unit/year, $h_{v}=\$ 0.3 /$ unit $/$ year, $h_{m}=\$ 0.1 /$ unit $/$ year, $s=\$ 0.3 /$ unit, $\theta_{1}=0.05, \theta_{2}=$ $0.05, r=1, C_{T}=\$ 100 / \mathrm{ship}, C_{t}=\$ 0.5 /$ unit, $p=$ $\$ 50 /$ unit, $c_{1}=\$ 0.5 /$ unit, $c_{2}=\$ 1 /$ unit, $u=\$ 1 /$ unit, $\alpha=0.5$, and $m(\xi)=1-e^{-0.01 \xi}$.

With the application of Algorithm 1, the solution procedure in Table 1 indicates that the manufacturer's optimal number of shipments, quantity of goods shipped, and preservation technology investment are 9, 425.968 units, and $\$ 101.588$, respectively. The retailer's optimal order quantity is $3,833.71$ units and the optimal joint total profit is $\$ 45,526.8$. Figure 4 displays a graphical illustration of the joint total profit function $\operatorname{JTP}\left(T_{b}, n, \xi\right)$ with respect to $T_{b}$ and $\xi$ for

Table 1. Solution procedure of Example 1.

\begin{tabular}{cccccc}
\hline $\boldsymbol{n}$ & $\boldsymbol{T}_{\boldsymbol{b}}$ & $\boldsymbol{q}$ & $\boldsymbol{Q}$ & $\boldsymbol{\xi}$ & $\boldsymbol{J T P}$ \\
\hline 8 & 0.4534 & 455.341 & 3642.72 & 99.3651 & 45524.6 \\
9 & 0.4243 & 425.968 & 3833.71 & 101.588 & $45526.8 \leftarrow$ \\
10 & 0.4001 & 401.473 & 4014.73 & 103.719 & 45521.4 \\
\hline
\end{tabular}

Note: "«" denotes the optimal solution generated by the proposed model.

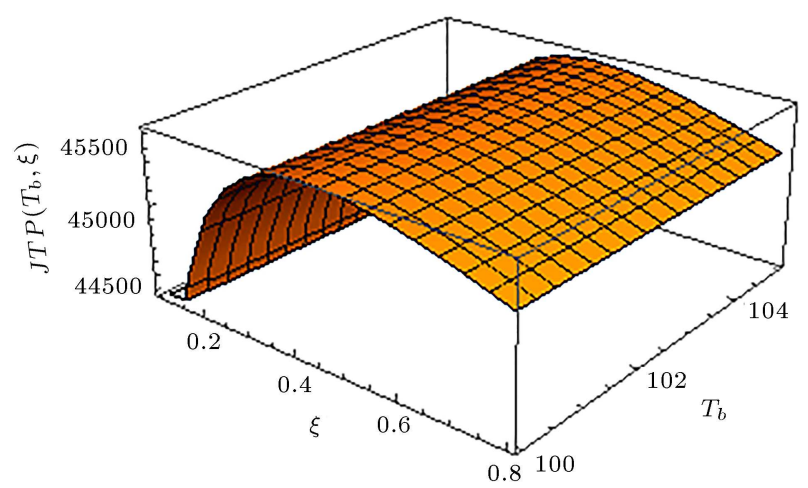

Figure 4. Graphical illustration of $\operatorname{JTP}\left(T_{b}, n, \xi\right)$ with respect to $T_{b}$ and $\xi$ for $n=9$.

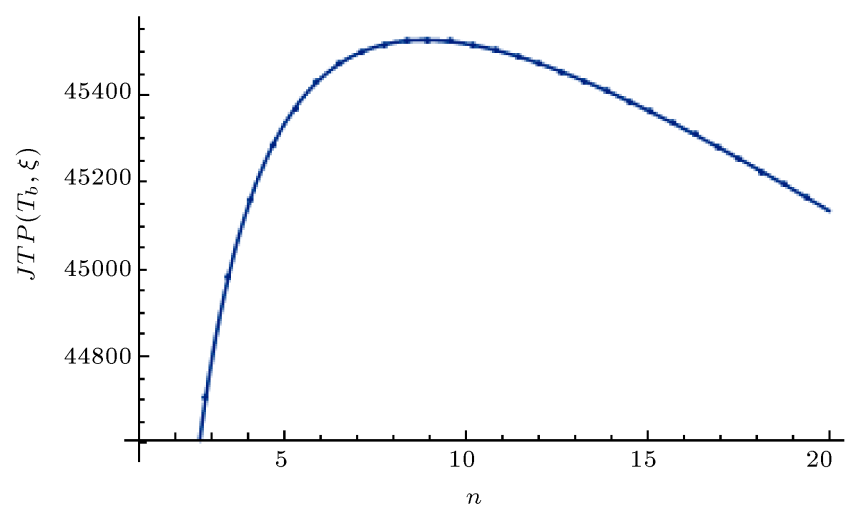

Figure 5. Graphical illustration $\operatorname{JTP}\left(T_{b}, n, \xi\right)$ versus $n$ for $\left(T_{b}, \xi\right)=(345.999,748.726)$.

$n=9$, and Figure 5 illustrates the graphical illustration of the joint total profit function $\operatorname{JTP}\left(T_{b}, n, \xi\right)$ versus $n$ for $\left(T_{b}, \xi\right)=(345.999,748.726)$. That is, the concavity of the joint total profit function can be verified, and the obtained solutions are optimal for maximizing the joint total profit function.

Example 2: A sensitivity analysis illustrates the effects of changes in the parameters related to retailers and manufacturers on the optimal solution. The data used are the same as those in Example 1, and the computational results are presented in Tables 2 and 3. Table 2 exhibits the sensitivity analysis with respect to the retailer's parameters, and the following observations can be made using it:

1. When the market demand $D$ increases, the optimal preservation technology investment $\xi^{*}$ and optimal order quantity $Q^{*}$ increase. Further, the optimal number of shipments $n^{*}$ gradually increases and the quantity of goods per shipment $q^{*}$ also increases with fixed delivery times. For the overall supply chain system, the demand rate has a positive effect on the joint total profit $J T P^{*}$. This indicates that if the supply chain system can effectively stimulate demand, it can improve the joint total profit.

2. In general, the increase in the retailer's fixed cost parameters (ordering cost of finished product $A_{R}$ and fixed shipping $\operatorname{cost} C_{T}$ ) will promote the increase in the optimal values of $\xi^{*}, q^{*}$, and $Q^{*}$, but lead to a decline in the optimal joint total profit. Further, it is worth noting that the optimal number of shipments will increase as the fixed shipping cost increases to a certain threshold (for example, $C_{T}=120$ in Table 2).

3. The optimal values of $\xi^{*}, q^{*}, Q^{*}$, and optimal joint total profit decrease when the retailer's holding cost $h_{b}$ increases. This is very intuitive because the retailer does not want to keep excess inventory when its holding cost is high. This will also reduce the 
Table 2. Sensitivity analysis of retailer's parameters in Example 1.

\begin{tabular}{|c|c|c|c|c|c|c|}
\hline Parameter & Value & $n^{*}$ & $\xi^{*}$ & $q^{*}$ & $Q^{*}$ & $J T P^{*}$ \\
\hline \multirow{5}{*}{$D$} & 800 & 8 & 85.8815 & 404.921 & 3239.36 & 36291.5 \\
\hline & 900 & 8 & 92.9478 & 430.703 & 3445.63 & 40908.0 \\
\hline & 1000 & 9 & 100.588 & 425.968 & 3833.71 & 45526.8 \\
\hline & 1100 & 9 & 107.507 & 448.126 & 4033.13 & 50148.1 \\
\hline & 1200 & 10 & 112.958 & 442.543 & 4425.43 & 54771.9 \\
\hline \multirow{5}{*}{$A_{R}$} & 80 & 9 & 99.0289 & 412.453 & 3712.08 & 45574.7 \\
\hline & 90 & 9 & 100.331 & 419.261 & 3773.35 & 45550.6 \\
\hline & 100 & 9 & 101.588 & 425.968 & 3833.71 & 45526.8 \\
\hline & 110 & 9 & 102.803 & 432.580 & 3893.22 & 45503.4 \\
\hline & 120 & 9 & 103.977 & 439.099 & 3951.89 & 45480.4 \\
\hline \multirow{5}{*}{$h_{b}$} & 0.4 & 9 & 102.715 & 432.096 & 3887.87 & 45548.2 \\
\hline & 0.45 & 9 & 102.148 & 428.998 & 3860.99 & 45537.5 \\
\hline & 0.5 & 9 & 101.588 & 425.968 & 3833.71 & 45526.8 \\
\hline & 0.55 & 9 & 101.036 & 423.003 & 3807.02 & 45516.2 \\
\hline & 0.6 & 9 & 100.490 & 420.100 & 3780.90 & 45505.7 \\
\hline \multirow{5}{*}{$\theta_{2}$} & 0.04 & 9 & 79.9595 & 425.912 & 3833.21 & 45548.5 \\
\hline & 0.045 & 9 & 91.3578 & 425.943 & 3833.49 & 45537.1 \\
\hline & 0.05 & 9 & 101.588 & 425.968 & 3833.71 & 45526.8 \\
\hline & 0.055 & 9 & 110.869 & 425.989 & 3833.90 & 45571.5 \\
\hline & 0.06 & 9 & 119.360 & 426.006 & 3834.06 & 45509.0 \\
\hline \multirow{5}{*}{$C_{T}$} & 80 & 9 & 99.0289 & 412.453 & 3712.08 & 45574.7 \\
\hline & 90 & 9 & 100.331 & 419.261 & 3773.35 & 45550.6 \\
\hline & 100 & 9 & 101.588 & 425.968 & 3833.71 & 45526.8 \\
\hline & 110 & 9 & 102.803 & 432.580 & 3893.22 & 45503.4 \\
\hline & 120 & 8 & 101.690 & 468.712 & 3749.70 & 45481.1 \\
\hline \multirow{5}{*}{$C_{t}$} & 0.4 & 9 & 101.226 & 425.998 & 3833.98 & 45632.5 \\
\hline & 0.45 & 9 & 101.408 & 425.983 & 3833.85 & 45579.6 \\
\hline & 0.5 & 9 & 101.588 & 425.968 & 3833.71 & 45526.8 \\
\hline & 0.55 & 9 & 101.769 & 425.953 & 3833.58 & 45474.0 \\
\hline & 0.6 & 9 & 101.949 & 425.938 & 3833.45 & 45421.1 \\
\hline \multirow{5}{*}{$p$} & 40 & 9 & 101.588 & 425.968 & 3833.71 & 35526.8 \\
\hline & 45 & 9 & 101.588 & 425.968 & 3833.71 & 40526.8 \\
\hline & 50 & 9 & 101.588 & 425.968 & 3833.71 & 45526.8 \\
\hline & 55 & 9 & 101.588 & 425.968 & 3833.71 & 50526.8 \\
\hline & 60 & 9 & 101.588 & 425.968 & 3833.71 & 55526.8 \\
\hline \multirow{5}{*}{$s$} & 0.24 & 9 & 101.371 & 425.986 & 3833.87 & 45590.2 \\
\hline & 0.27 & 9 & 101.480 & 425.977 & 3833.79 & 45558.5 \\
\hline & 0.3 & 9 & 101.588 & 425.968 & 3833.71 & 45526.8 \\
\hline & 0.33 & 9 & 101.697 & 425.959 & 3833.63 & 45495.1 \\
\hline & 0.36 & 9 & 101.805 & 425.950 & 3833.55 & 45463.4 \\
\hline
\end{tabular}


Table 3. Sensitivity analysis of the manufacturer's parameters in Example 1.

\begin{tabular}{|c|c|c|c|c|c|c|}
\hline Parameter & Value & $n^{*}$ & $\xi^{*}$ & $q^{*}$ & $Q^{*}$ & $J T P^{*}$ \\
\hline \multirow{5}{*}{$P$} & 6400 & 10 & 106.101 & 403.291 & 4032.91 & 45473.2 \\
\hline & 7200 & 9 & 102.619 & 426.750 & 3840.75 & 45502.3 \\
\hline & 8000 & 9 & 101.588 & 425.968 & 3833.71 & 45526.8 \\
\hline & 8800 & 8 & 98.5351 & 454.739 & 3637.91 & 45547.8 \\
\hline & 9600 & 8 & 97.8293 & 454.248 & 3633.98 & 45567.2 \\
\hline \multirow{5}{*}{$A_{M}$} & 400 & 9 & 100.211 & 418.618 & 3767.56 & 45552.8 \\
\hline & 450 & 9 & 100.906 & 422.308 & 3800.77 & 45539.8 \\
\hline & 500 & 9 & 101.588 & 425.968 & 3833.71 & 45526.8 \\
\hline & 550 & 9 & 102.258 & 429.600 & 3866.40 & 45514.0 \\
\hline & 600 & 9 & 102.915 & 433.203 & 3898.83 & 45501.2 \\
\hline \multirow{5}{*}{$S$} & 400 & 9 & 99.3586 & 414.151 & 3727.35 & 45568.7 \\
\hline & 450 & 9 & 100.491 & 420.098 & 3780.88 & 45547.6 \\
\hline & 500 & 9 & 101.588 & 425.968 & 3833.71 & 45526.8 \\
\hline & 550 & 9 & 102.653 & 431.765 & 3885.89 & 45506.3 \\
\hline & 600 & 9 & 103.687 & 437.491 & 3937.42 & 45486.1 \\
\hline \multirow{5}{*}{$v$} & 16 & 8 & 98.8446 & 455.385 & 3643.08 & 45589.9 \\
\hline & 18 & 8 & 99.1051 & 455.363 & 3642.90 & 45557.3 \\
\hline & 20 & 9 & 101.588 & 425.968 & 3833.71 & 45526.8 \\
\hline & 22 & 9 & 101.799 & 425.951 & 3833.56 & 45497.8 \\
\hline & 24 & 10 & 104.067 & 401.446 & 4014.46 & 45469.1 \\
\hline \multirow{5}{*}{$h_{v}$} & 0.24 & 9 & 113.272 & 462.084 & 4158.76 & 45645.7 \\
\hline & 0.27 & 9 & 107.211 & 442.885 & 3985.97 & 45585.0 \\
\hline & 0.30 & 9 & 101.588 & 425.968 & 3833.71 & 45526.8 \\
\hline & 0.33 & 9 & 93.3377 & 410.911 & 3698.20 & 45470.8 \\
\hline & 0.36 & 8 & 89.5038 & 425.208 & 3401.66 & 45418.1 \\
\hline \multirow{5}{*}{$h_{m}$} & 0.08 & 9 & 101.163 & 427.734 & 3849.60 & 45532.8 \\
\hline & 0.09 & 9 & 101.377 & 426.847 & 3841.63 & 45529.8 \\
\hline & 0.10 & 9 & 101.588 & 425.968 & 3833.71 & 45526.8 \\
\hline & 0.11 & 9 & 101.797 & 425.096 & 3825.86 & 45523.8 \\
\hline & 0.12 & 9 & 102.004 & 424.230 & 3818.07 & 45520.8 \\
\hline \multirow{5}{*}{$\theta_{1}$} & 0.040 & 9 & 101.036 & 426.014 & 3834.13 & 45527.4 \\
\hline & 0.045 & 9 & 101.313 & 425.991 & 3833.92 & 45527.1 \\
\hline & 0.050 & 9 & 101.588 & 425.968 & 3833.71 & 45526.8 \\
\hline & 0.055 & 9 & 101.863 & 425.945 & 3833.51 & 45526.5 \\
\hline & 0.060 & 9 & 102.137 & 425.923 & 3833.31 & 45526.3 \\
\hline \multirow{5}{*}{$c_{1}$} & 0.4 & 9 & 93.9544 & 426.622 & 3839.60 & 45638.8 \\
\hline & 0.45 & 9 & 97.8407 & 426.283 & 3836.55 & 45582.7 \\
\hline & 0.50 & 9 & 101.588 & 425.968 & 3833.71 & 45526.8 \\
\hline & 0.55 & 9 & 105.207 & 425.674 & 3831.07 & 45471.0 \\
\hline & 0.60 & 9 & 108.704 & 425.400 & 3828.60 & 45415.4 \\
\hline
\end{tabular}


Table 3. Sensitivity analysis of the manufacturer's parameters in Example 1 (continued).

\begin{tabular}{|c|c|c|c|c|c|c|}
\hline Parameter & Value & $n^{*}$ & $\xi^{*}$ & $q^{*}$ & $Q^{*}$ & $J T P^{*}$ \\
\hline \multirow{5}{*}{$c_{2}$} & 0.8 & 9 & 87.0352 & 427.257 & 3845.31 & 45750.3 \\
\hline & 0.9 & 9 & 94.5532 & 426.569 & 3839.12 & 45638.2 \\
\hline & 1.0 & 9 & 101.588 & 425.968 & 3833.71 & 45526.8 \\
\hline & 1.1 & 9 & 108.194 & 425.439 & 3828.95 & 45415.9 \\
\hline & 1.2 & 9 & 114.417 & 424.971 & 3824.74 & 45305.5 \\
\hline \multirow{5}{*}{$u$} & 0.8 & 9 & 101.553 & 425.971 & 3833.74 & 45537.2 \\
\hline & 0.9 & 9 & 101.571 & 425.970 & 3833.73 & 45532.0 \\
\hline & 1.0 & 9 & 101.588 & 425.968 & 3833.71 & 45526.8 \\
\hline & 1.1 & 9 & 101.606 & 425.967 & 3833.70 & 45521.6 \\
\hline & 1.2 & 9 & 101.624 & 425.965 & 3833.69 & 45516.4 \\
\hline \multirow{5}{*}{$\lambda$} & 0.04 & 9 & 100.870 & 427.755 & 3849.79 & 45572.5 \\
\hline & 0.045 & 9 & 101.229 & 426.863 & 3841.77 & 45549.7 \\
\hline & 0.05 & 9 & 101.588 & 425.968 & 3833.71 & 45526.8 \\
\hline & 0.055 & 9 & 101.950 & 425.070 & 3825.63 & 45503.7 \\
\hline & 0.06 & 9 & 102.314 & 424.170 & 3817.53 & 45480.3 \\
\hline \multirow{5}{*}{$r$} & 0.8 & 9 & 93.4684 & 428.425 & 3855.83 & 45644.9 \\
\hline & 0.9 & 9 & 97.6148 & 427.171 & 3844.54 & 45585.8 \\
\hline & 1.0 & 9 & 101.588 & 425.968 & 3833.71 & 45526.8 \\
\hline & 1.1 & 9 & 105.402 & 424.810 & 3823.29 & 45468.1 \\
\hline & 1.2 & 9 & 109.068 & 423.692 & 3813.22 & 45409.5 \\
\hline
\end{tabular}

preservation technology investment for the entire supply chain.

4. The higher the deterioration rate of finished goods, the higher the optimal preservation technology investment, quantity of goods per shipment, and order quantity and the lower the joint total profit. The deterioration rate is sensitive to the amount of preservation technology investment, but the impacts on the shipping and ordering quantity are very small. This result shows that when the preservation technology investment becomes an option, the impact of the deterioration rate on the shipping and ordering quantity will be reduced by investing in improving finished product deterioration.

5. When the retailer's unit cost parameters (variable shipping cost $C_{t}$ and inspection cost $s$ ) increase, the optimal preservation technology investment increases; however, the optimal shipping quantity, order quantity, and joint total profit decrease. In addition, the sensitivity of these parameters to the optimal solutions is very low.

6. The selling price $p$ has a positive effect on the optimal joint total profit, but no effect on $\xi^{*}, q^{*}$, and $Q^{*}$. It is obvious that the selling price is independent of decision variables of the proposed model and an increasing function of the joint total profit from Eq. (4).

According to Table 3, which presents the sensitivity analysis of the manufacturer's parameters, the following observations can be made:

1. As the manufacturer's production rate increases, the optimal preservation technology investment and order quantity decrease, while the optimal joint total profit increases. Further, the optimal number of shipments is reduced as the order quantity drops to a certain level due to the increase in manufacturer's production rate;

2. Similar to the retailer's fixed cost parameters, when the manufacturer's fixed costs (ordering cost of material and setup cost) increase, the optimal preservation technology investment, shipping quantity, and order quantity increase, while the optimal joint total profit decreases;

3. As the manufacturer's sales price increases, the optimal preservation technology investment increases, but the optimal shipping quantity and joint total profit decrease. Further, the optimal number of 
shipments will be increased as the order quantity rises to a certain level due to the increase in manufacturer's sales price. The results show that increased sales prices of the manufacturer will increase the order quantity, but it is not conducive to the entire supply chain;

4. The effect of the manufacturer's holding cost of finished goods on the best solution is consistent with that of retailer. The difference is that when the manufacturer's holding cost of finished goods increases to a certain threshold (for example $h_{v}=$ 0.36 in Table 3 ), it will reduce the number of shipments;

5. When the manufacturer's holding cost of material $h_{m}$, raw material cost $c_{1}$, production cost $c_{2}$, or treatment cost $u$ increase, the optimal preservation technology investment increases, while optimal shipping quantity, order quantity, and joint total profit are reduced. Further, changes in raw material and production costs are relatively sensitive to the amount of preservation technology investment;

6. The optimal preservation technology investment increases, while optimal joint total profit decreases followed by an increase in the deterioration rate of material, which is consistent with the deterioration rate of the finished goods. The difference is that the sensitivity of the deterioration rate of materials to the optimal solution is significantly lower. Further, the optimal shipping quantity and order quantity are reduced as the deterioration rate of material increases;

7. Whether the number of raw materials used to produce a finished product or the detective rate of the finished product increases, the optimal preservation technology investment increases, while optimal shipping quantity, order quantity, and joint total profit are reduced.

\section{Conclusions}

This study investigated a multistage supply chain production-inventory model for deteriorating items that accounted for collaborative investment in preservation technology. The main purpose of the study was to determine the manufacturer's optimal production and delivery policies as well as the retailer's optimal ordering and collaborative investing policies, which would maximize the joint total profit per unit time. Because of the complexity of the model, finding closedform solutions and directly checking the concavity of the profit function was difficult. Alternatively, the concavity of the proposed model was verified by numerical analysis and an algorithm was developed to obtain the solutions for the joint total profit per unit time. Furthermore, several numerical examples were presented to demonstrate the solution procedure and sensitivity analysis of the optimal solutions with respect to major parameters. From the numerical results, several management insights different from previous researches can be ascertained:

1. In general, the optimal shipping strategy is not easily affected. However, this proposed model shows that there are five parameters that may affect the optimal number of shipments: market demand, fixed shipping cost, production rate, manufacturer's sales price, and holding cost of finished goods;

2. The effect of deterioration rate of raw materials on the shipping quantity and order quantity is inconsistent with the deterioration rate of finished good. Further, when the collaborative preservation technology investment becomes an option, the effect of the deterioration rate of raw materials or finished goods on the shipping and ordering quantity will be reduced by investing in improving deterioration of raw materials or finished goods;

3. Though increased sales prices of the manufacturer will increase the order quantity, it is not conducive to the joint total profit of the entire supply chain;

4. The selling price is independent of decision variables of the proposed model and an increasing function of joint total profit. This is because the market demand considered in the model is constant;

5. When the raw material supply is considered in the production-inventory model, the increase in the number of raw materials used to produce a finished product will promote the optimal preservation technology investment, but decrease optimal shipping quantity, order quantity, and joint total profit. This is because the amount of finished goods produced by the original material quantity is reduced, which will increase the preservation technology investment and reduce joint total profit.

The proposed model could be extended in several ways. For example, the results indicate that the selling price has no effect on the optimal solution because it is an exogenous variable in the proposed model. Future research can treat the selling price as a decision variable and deal with the demand rate as a function of selling price. Furthermore, because of the various power levels and preferences among supply chain members, supply chains can be analyzed from competitive or cooperative viewpoints based on game theory concepts including Nash equilibrium, Stackelberg game, and Pareto optimality. Finally, the regulation of greenhouse gas emissions is a trend likely to affect enterprises' future business strategies. Therefore, the proposed model can be extended to account for the regulation of carbon emissions. 


\section{Acknowledgement}

The authors would like to thank the editor and anonymous reviewers for their valuable and constructive comments, which have led to a significant improvement in the manuscript. This research was partially supported by the Ministry of Science and Technology of the Republic of China under Grants MOST-106-2221-E231-002- MY2.

\section{References}

1. Goyal, S.K. "An integrated inventory model for a single supplier-single customer problem", Int. J. Prod. Res., 15(1), pp. 107-111 (1976).

2. Banerjee, A. "A joint economic-lot-size model for purchaser and vendor", Decision. Sci., 17(3), pp. 292311 (1986).

3. Goyal, S.K. "A joint economic-lot-size model for purchaser and vendor: a comment", Decision. Sci., 19(1), pp. 236-241 (1988).

4. Lu, L. "A one-vendor multi-buyer integrated inventory model”, Eur. J. Oper. Res., 81(2), pp. 312-323 (1995).

5. Goyal, S.K. "A one-vendor multi-buyer integrated inventory model: a comment", Eur. J. Oper. Res., 82(1), pp. 209-210 (1995).

6. Hill, R.M. "The single-vendor single-buyer integrated production-inventory model with a generalized policy", Eur. J. Oper. Res., 97(3), pp. 493-499 (1997).

7. Goyal, S.K. and Nebebe, F. "Determination of economic production-shipment policy for a single-vendorsingle-buyer system", Eur. J. Oper. Res., 121(1), pp. 175-178 (2000).

8. Kelle, P., Al-khateeb, F., and Miller, P.A. "Partnership and negotiation support by joint optimal ordering/setup policies for JIT", Int. J. Prod. Econ., 81-82, pp. 431-441 (2003).

9. Giri, B.C. and Roy, B. "A vendor-buyer integrated production-inventory model with quantity discount and unequal sized shipments", Int. J. Prod. Res., 16(1), pp. 1-13 (2013).

10. Sana, S.S. "A production-inventory model in an imperfect production process", Eur. J. Oper. Res., 200(2), pp. $451-464$ (2010).

11. Wu, O.Q. and Chen, H. "Optimal control and equilibrium behavior of production-inventory systems", Manag. Sci., 56(8), pp. 1362-1379 (2010).

12. Lin, Y.J. and Ho, C.H. "Integrated inventory model with quantity discount and price-sensitive demand", TOP, 19(1), pp. 177-188 (2011).

13. Ouyang, L.Y., Ho, C.H., Su, C.H., et al. "An integrated inventory model with capacity constraint and order-size dependent trade credit", Comput. Ind. Eng., 84, pp. 133-143 (2015).
14. Muniappan, P., Uthayakumar, R., and Ganesh, S. "A production inventory model for vendor-buyer coordination with quantity discount, backordering and rework for fixed life time products", J. Int. Prod. Econ., 33(6), pp. 355-362 (2016).

15. Bhunia, A.K. Shaikh, A.A., and Cárdenas-Barrón, L.E. "A partially integrated production-inventory model with interval valued inventory costs, variable demand and flexible reliability", Appl. Soft Comput., 55, pp. 491-502 (2017).

16. Teimoury, E. and Kazemi, S.M.M. "An integrated pricing and inventory model for deteriorating products in a two stage supply chain under replacement and shortage", Sci. Iran., 24(1), pp. 342-354 (2017).

17. Beck, A., Bilby, C., and Chapman, P. "Shrinkage in Europe: Stock loss in the fast-moving consumer goods sector", Secur. J., 15, pp. 25-39 (2002).

18. Ferguson, M.E., Lystad, E.D., and Alexopoulos, C. "Single stage heuristic for perishable inventory control in two-echelon supply chains", Unpublished Ph.D. Dissertation, Georgia Institute of Technology, USA (2006).

19. The Profit Experts, The 2011 Retail Profit Protection Report, (http://www.prlog.org/11378377-the2011-retail-profit-protection-repo rt.html) (2011).

20. Ghare, P.M. and Scharder, G.P. "A model for an exponentially decaying inventory", J. Ind. Engineering, 14(5), pp. 238-243 (1963).

21. Shen, Y.J., Shen, K.F., and Yang, C.T. "A production inventory model for deteriorating items with collaborative preservation technology investment under carbon tax", Sustainability, 11(18), p. 5027 (2019).

22. Hsu, P., Wee, H., and Teng, H. "Preservation technology investment for deteriorating inventory", Int. J. Prod. Econ., 124(2), pp. 388-394 (2010).

23. Dye, C.Y. and Hsieh, T.P. "An optimal replenishment policy for deteriorating items with effective investment in preservation technology", Eur. J. Oper. Res., 218(1), pp. 106-112 (2012).

24. Dye, C.Y. "The effect of preservation technology investment on a non-instantaneous deteriorating inventory model", Omega, 41(5), pp. 872-880 (2013).

25. He, Y. and Huang, H. "Optimizing inventory and pricing policy for seasonal deteriorating products with preservation technology investment", J. Ind. Engineering, 2013, pp. 1-7 (2013).

26. Zhang, J., Bai, Z., and Tang, W. "Optimal pricing policy for deteriorating items with preservation technology investment", J. Ind. Manag. Optim., 10(4), p. 1261 (2014).

27. Mishra, U., Cárdenas-Barrón, L.E., Tiwari, S., et al. "An inventory model under price and stock dependent demand for controllable deterioration rate with short- 
ages and preservation technology investment", Ann. Oper. Res., 254(1), pp. 165-190 (2017).

28. Mishra, U., Tijerina-Aguilera, J., Tiwari, S., et al. "Retailer's joint ordering, pricing and preservation technology investment policies for a deteriorating item under permissible delay in payments", Math. Probl. Eng., 2018, Article ID 6962417, 14 pages (2018).

29. Singh, S.R. and Sharm, S. "A global optimizing policy for decaying items with ramp-type demand rate under two-level trade credit financing taking account of preservation technology", Advances in Decision Sciences, 2013, pp. 1-12 (2013).

30. Shah, N.H., Shah, D.B., and Patel, D.G. "Optimal preservation technology investment, retail price and ordering policies for deteriorating items under trended demand and two level trade credit financing", J. Math. Modelling Algorithms Oper. Res., 14(1), pp. 1-12 (2015).

31. Yang C.T., Dye, C.Y., and Ding, J.F. "Optimal dynamic trade credit and preservation technology allocation for a deteriorating inventory model", Comput. Ind. Eng., 87, pp. 356-369 (2015).

32. Singh, S.R. and Rathore, H. "A two warehouse inventory model with preservation technology investment and partial backlogging", Sci. Iran., 23(4), pp. 19521958 (2016).

33. Tsao, Y.C. "Joint location, inventory, and preservation decisions for non-instantaneous deterioration items under delay in payments", Int. J. Syst. Sci., 47(3), pp. 572-585 (2016).

34. Bardhan, S., Pal, H., and Giri, B.C. "Optimal replenishment policy and preservation technology investment for a non-instantaneous deteriorating item with stockdependent demand", Oper. Res., 19, pp. 347-368 (2019).

35. Rust, R.T., Zahorik, A.J., and Keiningham, T.L. "Return on quality (ROQ): Making service quality financially accountable", J. Mark., 59(2), pp. 58-70 (1995).

36. Rosenblatt, M.J. and Lee, H.L. "Economic production cycles with imperfect production processes", IIE Trans., 18(1), pp. 48-55 (1986).

37. Kim, C.H. and Hong, Y. "An optimal production run length in deteriorating production processes", Int. J. Prod. Econ., 58(2), pp. 183-189 (1999).

38. Salameh, M.K. and Jaber, M.Y. "Economic production quantity model for items with imperfect quality", Int. J. Prod. Econ., 64(1-3), pp. 59-64 (2000).

39. Nobil, A.H., Cárdenas-Barrón, L.E., and Nobil, E. "Optimal and simple algorithms to solve integrated procurement-production-inventory problem without/with shortage", RAIRO-Oper. Res., 52(3), pp. $755-778$ (2018).

40. Sana, S.S. "A production-inventory model of imperfect quality products in a three-layer supply chain", Decis.
Support Syst., 50(2), pp. 539-547 (2011).

41. Treviño-Garza, G., Castillo-Villar, K.K., and Cárdenas-Barrón, L.E. "Joint determination of the lot size and number of shipments for a family of integrated vendor-buyer systems considering defective products", Int. J. Syst. Sci., 46(9), pp. 1705-1716 (2015).

42. Hsu, L.F. and Hsu, J.T. "Economic production quantity (EPQ) models under an imperfect production process with shortages backordered", Int. J. Syst. Sci., 47(4), pp. 852-867 (2016).

43. Jaggi, C.K., Cárdenas-Barrón, L.E., Tiwari, S., et al. "Two-warehouse inventory model for deteriorating items with imperfect quality under the conditions of permissible delay in payments", Sci. Iran., 24(1), p. 390 (2017).

44. Kang, C.W., Ullah, M., and Sarkar, B. "Optimum ordering policy for an imperfect single-stage manufacturing system with safety stock and planned backorder", Int. J. Adv. Manuf. Tech., 95(1-4), pp. 109-120 (2018).

45. Jain, S., Tiwari, S., Cárdenas-Barrón, L.E., et al. "A fuzzy imperfect production and repair inventory model with time dependent demand, production and repair rates under inflationary conditions", RAIRO-Oper. Res., 52(1), pp. 217-239 (2018).

46. Yang, C.T., Huang, C.H., and Ouyang, L.Y. "Optimal production and ordering strategies with defective items and allowable shortage under two-part trade credit", Sci. Iran., 26(1), pp. 503-521 (2019).

47. Lu, C.J., Yang, C.T., and Yen, H.F. "Stackelberg game approach for sustainable production-inventory model with collaborative investment in technology for reducing carbon emissions", J. Clean. Prod., 270, p. 121963 (2020).

\section{Biographies}

Chi-Chang Chang is a Professor of Medical Informatics School at the Chung Shan Medical University and also a consultant at Biomedical Industry Research Center, Smart Healthcare Committee at Chung-Shan Medical University Hospital. His primary research interests are in the areas of medical decision analysis, recurrent cancers, second primary cancers, shared medical decision-making, bioinformatics, and operation research. He has published over 100 peer-reviewed papers in reputed international journals and conferences. Prof. Chang is the Founding Chair of International Conference on Medical and Health Informatics (ICMHI) in 2017 and International Conference on Healthcare Service Management (ICHSM) in 2018. He has served as the Guest Editor for the journals including, International Journal of Environmental Research and Public Health, Frontiers in Genetics, International Journal Medical Sciences, Open Med, Therapeutics 
and Clinical Risk Management Journal of Universal Computer Science.

Chi-Jie Lu is currently a Professor at the Graduate Institute of Business Administration at Fu Jen Catholic University, Taiwan. He got his PhD in Industrial Engineering and Management from Yuan-Ze University, Taiwan. His research areas include machine learning and its applications, medical/healthcare informatics, time series forecasting, supply chain management, and quality management. He has published refereed articles in a number of journals that include International Journal of Production Economics, European Journal of Operational Research, Decision Support Systems, International Journal of Production Research, Journal of Cleaner Production, Pattern Recognition, Neurocomputing, Engineering Applications of Artificial Intelligence, Artificial Intelligence in Medicine, Journal of Intelligent Manufacturing, and Neural Computing and Applications.
Chih-Te Yang is a Professor at the Department of International Business at Chien Hsin University of Science and Technology in Taiwan. He earned his PhD from the Graduate Institute of Management Sciences at Tamkang University, Taiwan. His research interests are in the field of supply chain management, inventory management, and carbon emission technology. His articles have been published in Omega, International Journal of Production Economics, European Journal of Operational Research, Journal of the operational research society, Computers \& Industrial Engineering, Applied Mathematics and Computation, International Journal of Systems Science, Applied Sciences, European Journal of Industrial Engineering, Scientia Iranica, Asia-Pacific Journal of Operational Research, Mathematical Problems in Engineering, TOP, Journal of Scientific \& Industrial Research, RAIRO-Operations Research, Central European Journal of Operations Research, and International Journal of Information and Management Sciences. 